\title{
A CFD-DEM study of single bubble formation in gas fluidization of spherical and non-spherical particles
}

\author{
Siddhartha Shrestha and Zongyan Zhou* \\ Laboratory for Simulation and Modelling of Particulate Systems, Department of Chemical Engineering, Monash University, \\ Victoria 3800, Australia
}

\begin{abstract}
Bubble dynamics significantly affect the hydrodynamics of gas-solid fluidized bed since they influence the gas-solid mixing. In this study, simulations using CFD-DEM were carried out to characterize the bubble size and shape for a bubble formed at a single orifice in gas-solid fluidized bed. Impact of parameters such as jet velocity, orifice size and particle shape on bubble equivalent diameter and bubble aspect ratio were analysed and discussed. Bubble equivalent diameter was found to increase with increasing jet velocity, decreasing bed width to orifice width ratio, and particle shape deviating from spherical. The bubble shape illustrated by aspect ratio, was found to elongate more as it rise through the bed and then commence to expand horizontally after it was detached from the orifice. Aspect ratio was found to be closer to a circle for the bubble at higher jet velocity, lower orifice width to bed ratio and for non-spherical particles.
\end{abstract}

\section{Introduction}

Fluidization technology has been widely used in many industrial applications such as food, pharmaceuticals, energy and environment since they are associated with good heat and mass transfer. The flow behaviour in gassolid fluidized beds are very complex because of the fluidparticle and particle-particle interactions. Bubbles often exist in fluidized beds and are termed as "motor of fluidization"[1]. They govern hydrodynamics of fluidized beds, induce gas-solid mixing and promote heat and mass transfer [2]. Thus a good understanding of bubble formation at an orifice and its dynamics is essential to aid in design and development of gas-solid fluidized beds.

Various experimental studies have been carried out to portray bubble formation at an orifice [3] and to establish theoretical models $[4,5]$. In recent years numerical techniques have been widely used to study gassolid fluidized beds and also have become a significant approach to characterize bubble behaviour. Numerical techniques for gas-solid systems can be either continuumor discrete-based with respect to the solid phase. The former is called two-fluid model (TFM), where both gas and solid phases are considered continuous and fully interpenetrating. The latter is referred as discrete element model (DEM) where particle phase is modelled as discrete phase and gas phase as continuous. Several authors have used TFM to study bubble formation at a single orifice and its dynamics $[6,7]$. However, DEM simulations have advantage over TFM simulations because the solid phase is modelled much more accurately, in particular with respect to friction [8-10]. Olafe et al. [9] found that the bubble size and detachment times were sensitive to gas injection velocity, particle sizes and bed size. Rong et al. [11] studied the influence of particle properties (size and density), jet velocity and bed width on bubble characteristics. These parameters were found to affect the bubble dynamics. However, effect of particle shape and orifice size which can influence the bubble dynamics has not been previously investigated.

In this study, CFD-DEM is used to study the bubble formation at a single orifice and depict its size and shape with respect to jet velocity, orifice size and particle shape.

\section{Models and simulation conditions}

In CFD-DEM, the solid phase is based on the DEM and gas phase is modelled as TFM. The governing equations for particle $i$ with mass $m_{i}$ and moment of inertia $I_{i}$ can be written as

$m_{i} \frac{d v_{i}}{d t}=\mathbf{f}_{p f, i}+\sum_{j=1}^{k_{i}}\left(\mathbf{f}_{c, i j}+\mathbf{f}_{d, i j}\right)+m_{i} \mathbf{g}$

$I_{i} \frac{d \omega_{i}}{d t}=\sum_{j=1}^{k_{i}}\left(\mathbf{M}_{t, i j}+\mathbf{M}_{r, i j}+\mathbf{M}_{n, i j}\right)$

where $\mathbf{v}_{\mathbf{i}}$ and $\omega_{\mathbf{i}}$ are the translational and angular velocities of the particle, respectively, and $k_{i}$ is the number of particles interacting with the particle. The forces involved are: particle fluid interaction force $\mathbf{f}_{\mathrm{pf}, \mathrm{i}}$, the gravitational force $\mathbf{m i g}$, and the inter-particle forces between the particles, which include elastic force $\mathbf{f}_{\mathrm{c}, \mathrm{jj}}$ and viscous damping force $\mathbf{f}_{\mathrm{d}, \mathrm{j} j}$. The torques acting on particle $i$ by particle $j$ include: $\mathbf{M}_{t, \mathrm{ij}}$ generated by the tangential force, $\mathbf{M}_{\mathrm{r}, \mathrm{ij}}$ commonly known as the rolling friction torque, and also the torque $\mathbf{M}_{\mathrm{n}, \mathrm{ij}}$ generated by the normal force when the normal force does not pass through the particle centre. The governing equations for gas phases are given as, $\frac{\partial \varepsilon_{f}}{\partial t}+\nabla \cdot\left(\varepsilon_{f} \mathbf{u}\right)=0$ $\frac{\partial\left(\rho_{f} \varepsilon_{f} \mathbf{u}\right)}{\partial t}+\nabla \cdot\left(\rho_{f} \varepsilon_{f} \mathbf{u u}\right)=-\nabla p-\mathbf{F}_{p f}+\nabla \cdot\left(\varepsilon_{f} \boldsymbol{\tau}\right)+$

$$
\rho_{f} \varepsilon_{f} \mathbf{g}
$$

* Corresponding author: zongyan.zhou $@$,monash.edu 
where $\mathbf{u}, \rho_{f}$ and $p$ are the fluid velocity, density and pressure, respectively. $\mathbf{F}_{p f}$ is the volumetric particle-fluid interaction force in a computational CFD cell of volume, $\Delta \mathrm{V} . \boldsymbol{\tau}$ and $\varepsilon_{f}$ are the fluid viscous stress tensor and local porosity.

For details regarding the governing equations and the equations to calculate the interaction forces and torques, refer to the literatures $[12,13]$. The bed geometry used in this work is a slot model with periodic boundary conditions applied to the front and rear direction. For such a geometry, two-dimensional CFD and three dimensional DEM are employed as used elsewhere [12]. The bed is produced by generating particles randomly. Particles are generated randomly at different heights and allowed to come to rest to form a bed [13]. The bed is then fluidized by gas from central orifice at the bottom which is of size 4 CFD cells $(0.001 \mathrm{~m})$. Table 1 lists the parameters including the bed geometry, physical properties of particles and fluid used in the simulation.

Table 1. Various parameters used in simulation

\begin{tabular}{ll}
\hline Variable & Values \\
\hline \multicolumn{1}{c}{ Bed geometry } & \\
Bed width $(\mathrm{x})$ & $0.02 \mathrm{~m}$ \\
Bed height $(\mathrm{z})$ & $0.08 \mathrm{~m}$ \\
Bed thickness $(\mathrm{y})$ & $0.0004 \mathrm{~m}$ \\
Orifice width & 4 CFD cells \\
CFD cells $(\mathrm{x}, \mathrm{z})$ & $320 \times 80 \mathrm{cells}$ \\
CFD cell size $(\Delta \mathrm{x}, \Delta \mathrm{z})$ & $0.00025 \mathrm{~m}$ \\
$\quad$ Particle Properties & \\
Shape & Oblate, spherical, prolate \\
Aspect ratio, $\eta$ & $0.75,0.85,1,1.15,1.30$ \\
Umf, m/s & $0.003,0.0035,0.005$, \\
& $0.004,0.003$ \\
Number of Particles, $\mathrm{N}_{\mathrm{p}}$ & 100,000 \\
Particle size, $\mathrm{d}_{\mathrm{p}}$ & $100 \mu \mathrm{m}$ \\
Particle density, $\rho_{\mathrm{p}}$ & $1450 \mathrm{~kg} / \mathrm{m}^{3}$ \\
Particle-particle sliding & 0.4 \\
friction, $\mu_{\mathrm{s}}$ & \\
Particle-wall sliding & 0.4 \\
friction, $\mu_{\mathrm{r}}$ & \\
Normal damping & 0.3 \\
co-efficient, $\mathrm{c}_{\mathrm{n}}$ & \\
Young's modulus, E & $1 \times 10^{7} \mathrm{~Pa}$ \\
Poisson ratio, $v$ & 0.3 \\
Time step, $\Delta \mathrm{t}$ & $1.6 \times 10^{-6}$ \\
$\quad$ Gas properties & $1.205 \mathrm{~kg} / \mathrm{m}^{3}$ \\
Density & $1.8 \times 10^{-5} \mathrm{~Pa} \mathrm{~s}$ \\
Viscosity & \\
\hline
\end{tabular}

\section{Results and discussion}

In order to extract the bubble characteristics, bubble boundary has to be defined which was evaluated from the simulated void fraction data. The threshold void fraction was taken as 0.8 , and the regions above $\varepsilon=0.8$ were defined as bubbles. Assuming bubbles to be two dimensional, the bubble equivalent diameter was defined as follows:

$$
D_{e}=\sqrt{4 A / \pi}
$$

where $A$ is the bubble area. The aspect ratio of a bubble describes the closeness of bubble shape to circle and is defined as:

$$
\sigma=D_{v} / D_{h}
$$

where $D_{v}$ and $D_{h}$ represents the vertical and horizontal diameter through bubble centre respectively.

\subsection{Influence of Jet velocity}

Different jet velocities were injected from the centre of bed with orifice size equal to 4 CFD cells (i.e. $0.001 \mathrm{~m}$ of orifice width) to examine its effect. Fig. 1 shows formation of DEM bubbles at different times after injection of jet velocity of 0.1 (a-e), 0.15 (f-j) and 0.25 (ko) $\mathrm{m} / \mathrm{s}$. For all the injection velocities applied, the bubbles detach the distributor around 0.046s. The bubble detachment time is unaffected by the injection velocity. Similar conclusion was shown in previous study [10]. However the rise of the bubble, size and shape are significantly affected by the jet velocity. It can be seen from Fig. 1 (c, h and $\mathrm{m}$ ) that at the same time the bubble for the higher velocity is at much higher level in the bed than for the lower velocity. Moreover, at $0.11 \mathrm{~s}$ (Fig. $1 \mathrm{~d}, \mathrm{i}$ and $\mathrm{n}$ ), the bubble for $\mathrm{U}=0.25 \mathrm{~m} / \mathrm{s}$ is at the top of the bed while the bubble for $U=0.1 \mathrm{~m} / \mathrm{s}$ is at the middle of the bed. This might be because the bubble rise velocity is greatly affected by the size of the bubble which is generally expressed as the bubble equivalent diameter. In literature, most of the correlations developed to calculate the single bubble rise velocity is correlated with the bubble equivalent diameter [14]. However, in this paper we do not intend to investigate the single bubble rise velocity but rather limit our investigation to the size and shape of the first bubble formed and the effect of several parameters such as jet velocity, orifice size and particle shape.

Fig. 2 shows the effect of jet velocity on bubble equivalent diameter for the formation of the first bubble. The bubble size grows with time when it rises through the bed to a maximum value and then remains approximately constant. At the same time the bubbles formed for large velocity is larger. This result is consistent with the expression for bubble mass balance and literature results $[3,9]$. Fig. 3 shows the calculated bubble aspect ratio during the bubble growth for different jet velocity. For all jet velocity, as the bubble rises through the bed it expands in the vertical direction thereby becomes more and more elongated. However, for lower jet velocity, the elongation is more significant and existing for long time. After the bubble is detached, the bubble stretches in the horizontal direction due to development of wake which results in the decrease of the aspect ratio. It can be established that for the higher velocity, the bubble tends to be more spherical when it is rising through the bed.

\subsection{Effect of orifice size}

In order to assess the effect of orifice size on the bubble characteristics, the CFD cell size in the centre of 


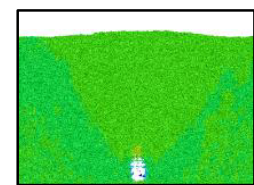

(a) $0.046 \mathrm{~s}$

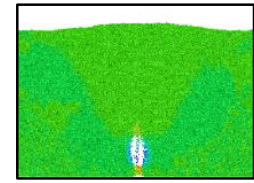

(b) $0.062 \mathrm{~s}$

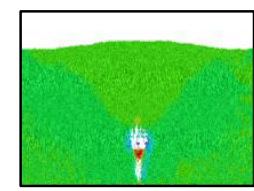

(c) $0.084 \mathrm{~s}$

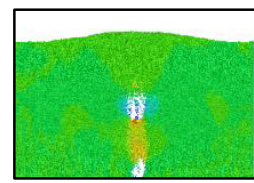

(d) $0.11 \mathrm{~s}$

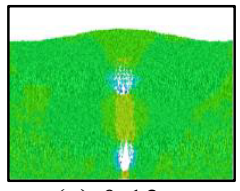

(e) $0.13 \mathrm{~s}$

$\mathrm{U}=0.10 \mathrm{~m} / \mathrm{s}$

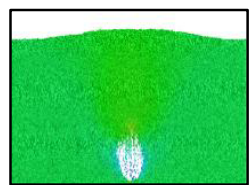

(f) $0.046 \mathrm{~s}$

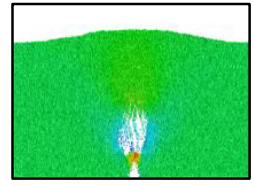

(g) $0.062 \mathrm{~s}$

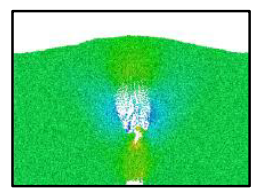

(h) $0.084 \mathrm{~s}$

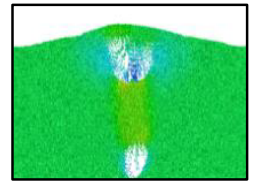

(i) $0.11 \mathrm{~s}$

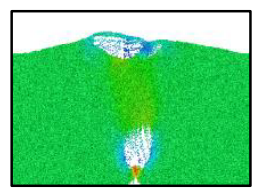

(j) $0.13 \mathrm{~s}$

$\mathrm{U}=0.15 \mathrm{~m} / \mathrm{s}$

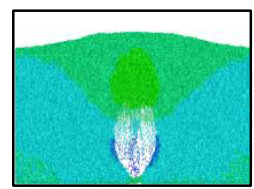

(k) $0.046 \mathrm{~s}$

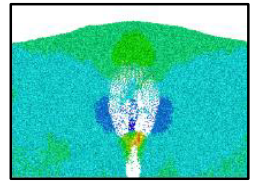

(1) $0.062 \mathrm{~s}$

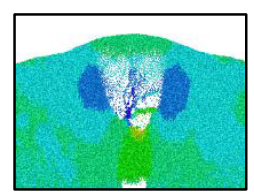

(m) $0.084 \mathrm{~s}$

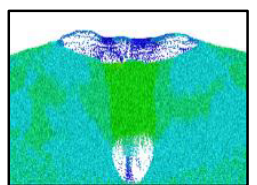

(n) $0.11 \mathrm{~s}$

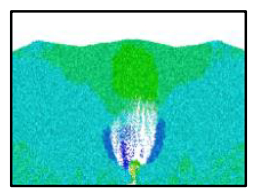

(o) $0.13 \mathrm{~s}$

$\mathrm{U}=0.25 \mathrm{~m} / \mathrm{s}$
Fig. 1. DEM bubbles at different times after injection of jet velocity of $U=0.10 \mathrm{~m} / \mathrm{s}(\mathrm{a}-\mathrm{e}), \mathrm{U}=0.15 \mathrm{~m} / \mathrm{s}(\mathrm{f}-\mathrm{j})$ and $\mathrm{U}=0.25$ $\mathrm{m} / \mathrm{s}(\mathrm{k}-\mathrm{o})$

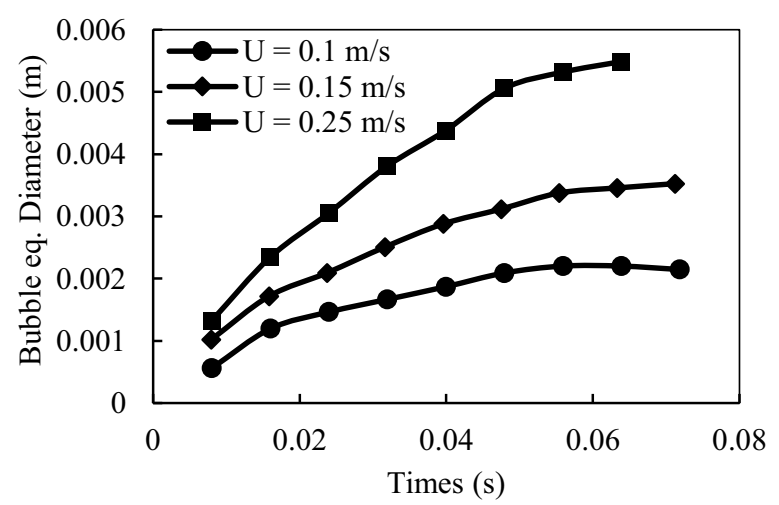

Fig. 2. Effect of jet velocity on bubble equivalent diameter.

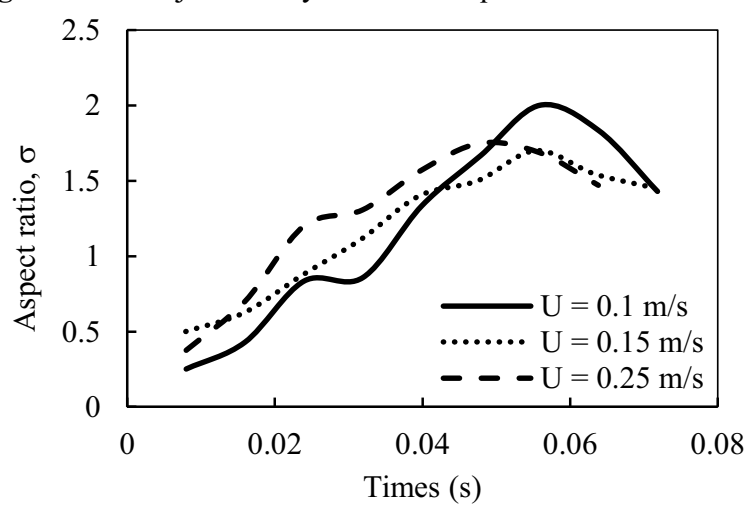

Fig. 3. Bubble aspect ratio for different jet velocity. the bed which represented the orifice size in the simulations were varied while jet velocity was maintained at $0.1 \mathrm{~m} / \mathrm{s}$. The base case was 4 CFD cells which is equal to $0.001 \mathrm{~m}$ orifice width and bed width to orifice width ratio of 20. CFD cell size was increased from 4 to 6 and 8 which is equal to $0.0015 \mathrm{~m}$ and $0.002 \mathrm{~m}$, and bed width to orifice width ratio of 13.3 and 10 , respectively. Fig. 4 shows the bubbles at $0.046 \mathrm{~s}$ for different orifice size for jet velocity of $0.1 \mathrm{~m} / \mathrm{s}$, indicating that the bubbles formed for larger orifice size is larger. Similar result is also illustrated by Fig. 5 which shows the effect of increasing orifice size on the growth of bubble equivalent diameter. Increasing the orifice size increases the bubble size. Figs. 4 and 5 shows that as the bed width to orifice width ratio decreases, the size of the bubble increases. A case in which orifice size was decreased to that of base case, i.e. with orifice size equal to 2 CFD cells was also simulated, the results are not shown here. However, in this case no bubbles were formed.

Fig. 6 shows the effect of orifice size on the bubble aspect ratio at jet velocity of $0.1 \mathrm{~m} / \mathrm{s}$. As the bubble rises through the bed, the bubble aspect ratio keeps increasing, and indicates that the bubble is growing in the vertical direction. This is similar to previous case for all orifice sizes. But the shape of the bubble formed with increasing the size of the orifice or decreasing the bed width to orifice width ratio tend to be more spherical. Bubble formed after the detachment from the orifice for orifice size of 8 CFD cell was the closest to spherical with bubble aspect ratio of 1.25 .

\subsection{Effect of particle shape}

To date, simulation studies related to the formation of bubble at single orifice are carried out with spherical particles. This cannot fully represent the reality since in practice the particles are mostly non-spherical, of either regular or irregular shapes [12]. Particle shape is one of the most important particle properties which can affect the flow dynamics and influence the size and shape of the bubble. To investigate the effect of particle shape, spheroids are considered, with its aspect ratio (AR) varying from 0.75 to 1.30 . The aspect ratio of spheroids/ellipsoids is defined as the ratio of the polar to equatorial lengths. DEM study of ellipsoidal particles have been well developed [12]. In this study, bed of spheroid particles with AR of $0.75,0.85,1.15$ and 1.30 were generated and then gas was injected at jet velocity of $0.1 \mathrm{~m} / \mathrm{s}$ from the centre of the bed with orifice width of 4 CFD cells.

Fig. 7 shows the effect of different particle shape (characterized by AR) on the bubble size. The bubble equivalent diameter is the smallest for spherical particles. As the AR deviates from 1 (either greater or smaller than 1), the size of the bubble increases. This might be because when the $\mathrm{AR}$ is deviating from 1, the particle-particle interaction and fluid drag becomes relatively weak. In addition, this can also be related to the effect of minimum fluidization velocity. Particles with lower minimum fluidization velocity have been shown to generate larger bubbles $[7,11]$. Decreasing AR from 1 up to 0.25 and 
increasing AR from 1 up to 2 have shown to decrease the minimum fluidization velocity [13]. Bubbles for $\mathrm{AR}=$ 0.75 and $\mathrm{AR}=1.30$ have the highest bubble equivalent diameter since they have the lowest minimum fluidization velocity (refer Table 1).

Fig. 8 shows the effect of particle shape on bubble aspect ratio. It can be seen that the bubble aspect ratio grows in similar way for all the particles, however for ellipsoidal particles the decrease in aspect ratio is not as sharp as for the spherical particles. Bubble for particles deviating from $\mathrm{AR}=1$ tend to be closer to spherical than bubble for $\mathrm{AR}=1$.

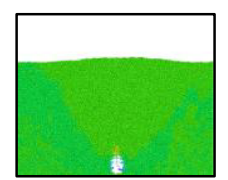

(a) 4 CFD cells

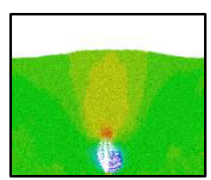

(b) 6 CFD Cells

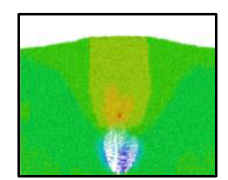

(c) 8 CFD Cells
Fig. 4. DEM bubbles at $0.046 \mathrm{~s}$ for different orifice size at jet velocity of $0.10 \mathrm{~m} / \mathrm{s}$.

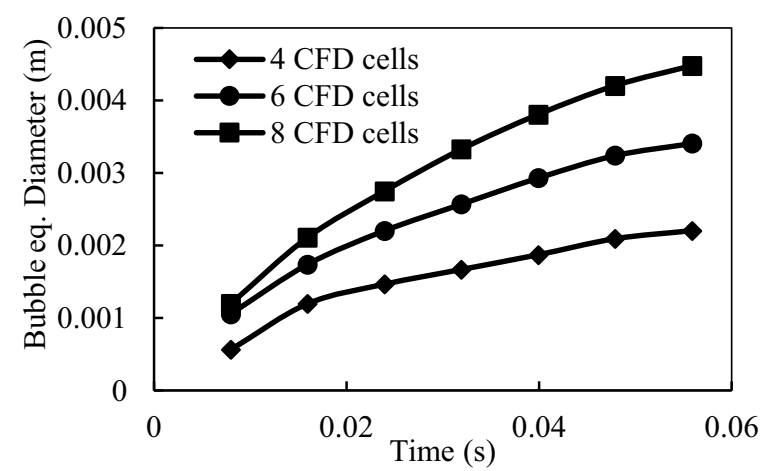

Fig. 5. Effect of orifice size on bubble equivalent diameter, when jet velocity $=0.10 \mathrm{~m} / \mathrm{s}$.

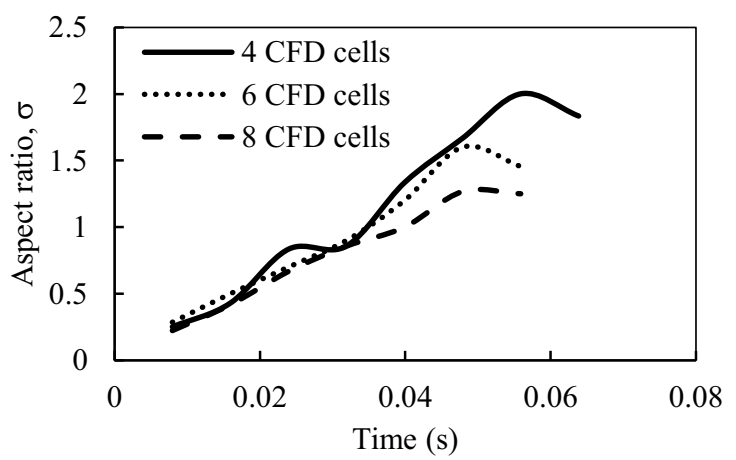

Fig. 6. Effect of orifice size on bubble aspect ratio, when jet velocity $=0.10 \mathrm{~m} / \mathrm{s}$.

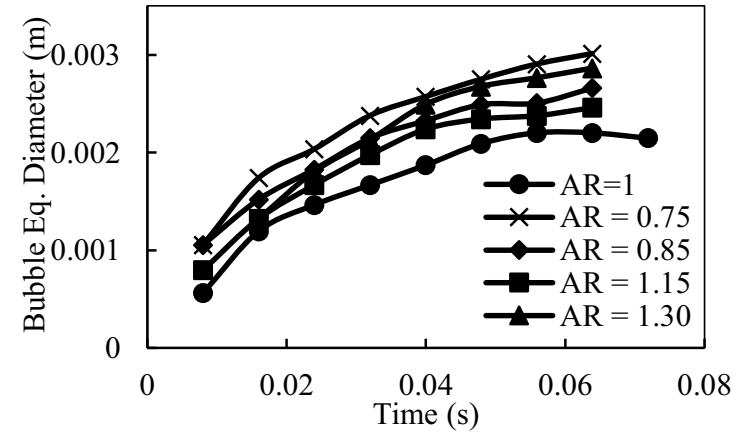

Fig. 7. Effect of particle shape on bubble equivalent diameter, when jet velocity $=0.10 \mathrm{~m} / \mathrm{s}$.

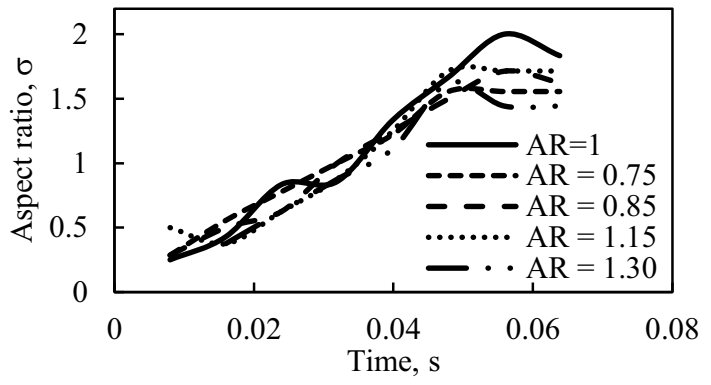

Fig. 8. Effect of particle shape on bubble aspect ratio, when jet velocity $=0.10 \mathrm{~m} / \mathrm{s}$.

\section{Conclusion}

Formation of a bubble at a single orifice was investigated using CFD-DEM to study the bubble characteristics such as bubble equivalent diameter and bubble aspect ratio. Effect of different parameters such as jet velocity, orifice size and particle shape on bubble characteristics were explored. The bubble equivalent diameter which delineates the size of the bubble was found to increase with increasing jet velocity and orifice width. It was also found to be greater for the non-spherical particles whose aspect ratio was deviating from 1 . The bubble aspect ratio was found to elongate in the vertical direction as the bubble rose through the bed, and it expanded in the horizontal direction when it was detached from the orifice. The bubbles for higher jet velocity, large orifice size and for non-spherical particles tend to be more spherical.

\section{References}

[1] M. Rüdisüli, PhD. Thesis ETH ZURICH (2012).

[2] A. Busciglio, G. Vella, G. Micale, L. Rizzuti, Chem. Eng, J., 140 (2008) 398-413.

[3] A.D. Lotfabad, S. Movahedirad, M. Sadeghi, Iran. J. Chem. Eng. (IJChE), 13 (2016) 61.

[4] D. Harrison, L. Leung, Chem. Eng. Res. Des., 39 (1961) 409-414.

[5] H.S. Caram, K.-K. Hsu, Chem. Eng. Sci., 41 (1986) 1445-1453.

[6] J. Kuipers, W. Prins, W. Van Swaaij, Chem. Eng. Sci., 46 (1991) 2881-2894.

[7] J. Nieuwland, M. Veenendaal, J. Kuipers, W. Van Swaaij, Chem. Eng. Sci., 51 (1996) 4087-4102.

[8] D. Gera, M. Gautam, Y. Tsuji, T. Kawaguchi, T. Tanaka, Powder Technol., 98 (1998) 38-47.

[9] O.O. Olaofe, M.A. van der Hoef, J.A.M. Kuipers, Chem. Eng. Sci., 66 (2011) 2764-2773.

[10] J.K. Pandit, X. Wang, M. Rhodes, Chem. Eng. Sci., 62 (2007) 159-166.

[11] L.-w. Rong, J.-m. Zhan, C.-l. Wu, Adv. Powder Technol., 23 (2012) 398-405.

[12] Z. Zhou, D. Pinson, R. Zou, A. Yu, Chem. Eng. Sci., 66 (2011) 6128-6145.

[13] J. Gan, Z. Zhou, A. Yu, AIChE Journal, 62 (2016) 62-77.

[14] S. Karimipour, T. Pugsley, Powder Technol., 205 (2011) 1-14. 